\title{
Treatment Eligibility and Therapeutic Responses of an Ecuadorian Population at High Cardiovascular Risk Based on the ATP III Guidelines
}

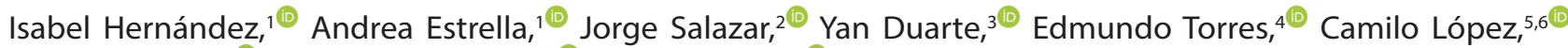 \\ Santiago Terán, ${ }^{7 \oplus}$ Alejandra Mendoza, ${ }^{7 \oplus}$ Enrique Terán ${ }^{1,7}{ }^{1}$ \\ Facultad de Enfermería, Pontificia Universidad Católica del Ecuador, ${ }^{1}$ Quito - Ecuador \\ Servicio de Endocrinología, Hospital de Especialidades Eugenio Espejo, ${ }^{2}$ Quito - Ecuador \\ Servicio de Cardiología, Hospital Luis Vernaza, ${ }^{3}$ Guayaquil - Ecuador \\ Servicio de Medicina Interna, Hospital Carlos Andrade Marín, ${ }^{4}$ Quito - Ecuador \\ Servicio de Endocrinología, Hospital Teodoro Maldonado Carbo, ${ }^{5}$ Guayaquil - Ecuador \\ Facultad de Medicina, Universidad de Guayaquil, ${ }^{6}$ Guayaquil - Ecuador
}

Colegio de Ciencias de la Salud, Universidad San Francisco de Quito, ${ }^{7}$ Quito - Ecuador

\section{Abstract}

Background: The Adult Treatment Panel III (ATPIII) guidelines aim to reduce cardiovascular morbidity and mortality. In Ecuador, 20\% of people have high LDL cholesterol levels, and 39\% have high triglyceride levels.

Objective: To analyze lipid-lowering regimens in Ecuadorian patients and determine the achievement rate of the ATPIII goals for lipid profile.

Methods: Using a retrospective analysis, 385 subjects older than 30 years, who received pharmacological treatment for dyslipidemia for at least three months was randomly selected from institutions at two large cities in Ecuador. Data were collected from patients' medical records and analyzed by chi-square test or paired t-test; p-values less than 0.05 were considered significant.

Results: Baseline total cholesterol values were above $200 \mathrm{mg} / \mathrm{dL}$ in $75 \%$ of subjects, LDL-c values above $129 \mathrm{mg} / \mathrm{dL}$ in $83 \%$ of subjects and triglycerides values above $150 \mathrm{mg} / \mathrm{dL}$ in $79 \%$ of subjects. Most $(\mathrm{n}=253,95.8 \%)$ patients at very high cardiovascular risk were taking statins, $50 \%$ of them atorvastatin. Considering the ATPIII guidelines' goals, only 24 subjects $(19 \%)$ at high CV risk achieved an LDL-c $<100 \mathrm{mg} / \mathrm{dl}$, while a significantly lower percentage $(\mathrm{p}=0.04)$ of patients at very high risk reached an LDL-c $<70 \mathrm{mg} / \mathrm{dl}(11 \% ; n=30)$.

Conclusion: These data indicate a low rate of compliance with the ATPIII guidelines, independent of the medication used or duration of the treatment. This may be attributed to the prescription of low doses of medication and a therapy targeting isolated lipid fractions rather than a complete lipid profile. (Int J Cardiovasc Sci. 2020; 33(4):371-376)

Keywords: Cardiovascular Diseases/prevention and control; Cholesterol; Triglicerides; Sedentarism; Tabaquism; Lifestyle; Dyslipidemia; Patient Compliance.

\section{Introduction}

The development of noncommunicable chronic diseases is associated with smoking, sedentary lifestyle and nutritional factors, and their detrimental effects can be reduced by a healthy lifestyle. ${ }^{1,2}$ In Ecuador, health care of patients with diabetes mellitus, dyslipidemia, and hypertension accounts for the majority of physicianpatient appointments and hospital discharge in the last twenty years. ${ }^{3}$ Recently, the National Health and Nutrition Survey (Encuesta Nacional de Salud y Nutrición - ENSANUT) presented by the Ecuadorian

Mailing Address: Enrique Teran, MD, PhD

Colegio de Ciencias de la Salud - Universidad San Francisco de Quito - Diego de Robles, s/n. Postal Code: 170157, Quito - Ecuador.

E-mail: eteran@usfq.edu.ec 
Ministry of Public Health showed that dyslipidemia is present in $19.9 \%$ of people below 60 years old while hypertriglyceridemia reaches $38.7 \%$ nationwide. ${ }^{4}$

For more than a decade, treatment of dyslipidemia by the medical community has been based on the National Cholesterol Education Program (NCEP) Adult Treatment Panel III guidelines (ATP III and subsequent updates). ${ }^{5}$ This approach relied heavily on the Framingham Heart Risk Score as a predictor of 10-year risk of coronary heart disease (CHD) events, specifically myocardial infarction and CHD-related death. Moreover, ATPIII provides therapy guidelines for low-density lipoprotein cholesterol (LDL-c) and non-high-density lipoprotein cholesterol (non-HDL-c) established based on patients' predicted risk and related comorbidities. In general, these guidelines recommend aggressive treatment of LDL-c of patients at higher risk, with specific LDL-c targets for each risk category. ${ }^{5}$

Since the late 1980s, 3-hydroxy-3-methylglutarylcoenzyme A (HMG-CoA) reductase inhibitors ('statins') has been used as the primary treatment of hypercholesterolemia. A pooled analysis of the Cholesterol Treatment Trialists' Collaboration (CTTC) showed that every $1 \mathrm{mmol} / \mathrm{L}$ (38.67 $\mathrm{mg} / \mathrm{dL}$ ) reduction in LDL-c with statin therapy was associated with a reduction in any major cardiovascular event by $21 \%$ to $28 \%{ }^{6}$

The present study analyzes different lipid-lowering regimens in Ecuadorian patients at high and very high cardiovascular risk, to determine if ATPIII guidelines achieve their treatment goals.

\section{Materials and methods}

This was a retrospective study approved by the institutional review board of the Universidad San Francisco de Quito (2015-044IN). A sample of patients' medical records was calculated (5\% precision, 95\% confidence interval and 50\% variability) and obtained from six hospitals in the two main cities of Ecuador assuming a rate of 2:1 between public and private institutions. In Quito city, the hospitals that participated in the study "Hospital de Especialidades Eugenio Espejo" (public hospital, run by the Ministry of Public Health), "Hospital Carlos Andrade Marín" (public hospital, run by the social security administration), and "Hospital de Los Valles" (private hospital). In Guayaquil, the hospitals included were "Hospital Luis Vernaza" (public hospital, run by the Junta Beneficencia - Charity Board), "Hospital
Teodoro Maldonado Carbo" (public hospital, run by the social security administration), and "Clinica Kennedy" (private hospital).

Medical records of subjects that met the following criteria were included in our analysis: (a) subjects that attended an internal medicine, cardiology or endocrinology outpatient clinics, (b) subjects older than 30 years (c) patients with a diagnosis of dyslipidemia evidenced by laboratory tests (d) subjects undergoing pharmacological treatment at one of the mentioned hospitals for at least three months. Subjects that met the above criteria were selected per institution using a random number generator (www.random.org) and data from the medical records were collected using forms specially designed for this study.

According to the ATP III algorithm, subjects are placed in one of three risk categories: (1) established CHD and CHD risk equivalents, (2) multiple (2+) risk factors, and (3) zero to one (0-1) risk factor. CHD risk equivalents include noncoronary forms of clinical atherosclerotic disease, diabetes, and multiple (2+) CHD risk factors with 10-year risk for CHD > 20\%. Subjects with CHD or CHD risk equivalents can be categorized as high risk. The goal for LDL-lowering therapy in high-risk patients is an LDL-c level $<100 \mathrm{mg} / \mathrm{dL}$. According to ATP III, for a baseline or on-treatment LDL-c $<100 \mathrm{mg} / \mathrm{dL}$, no further LDL-lowering therapy is recommended. For all high-risk patients with LDL-c levels > $100 \mathrm{mg} / \mathrm{dL}$, LDL-lowering dietary therapy should be initiated. ${ }^{5}$

Other factors that place subjects in the category of very high risk are the presence of established CVD plus (1) multiple major risk factors (especially diabetes), (2) severe and poorly controlled risk factors (especially continued cigarette smoking), (3) multiple risk factors of the metabolic syndrome (especially high triglycerides $>200 \mathrm{mg} / \mathrm{dL}$ plus non-HDL-C > $130 \mathrm{mg} / \mathrm{dL}$ with low HDL-C $[<40 \mathrm{mg} / \mathrm{dL}]$ ), and (4) patients with acute coronary syndromes. ${ }^{5}$

\section{Statistical analysis}

Continuous variables with a normal distribution, assessed by the Shapiro-Wilk test, were described as mean and standard deviation while categorical variables were presented as frequencies. Data were analyzed using the SPSS, using the chi-square test for categorical variables and the paired t-test for the continuous variables. A p-value less than 0.05 was considered as significant. 


\section{Results}

A total of 385 patients were recruited, with an average age of $59.8 \pm 13.2$ years; $46 \%(n=178)$ were male and $68 \%$ of them were at a very high risk of cardiovascular disease.

Analysis of baseline lipid profile showed total cholesterol levels higher than the desirable $(<200 \mathrm{mg} / \mathrm{dL})$ in $75 \%$ of subjects and LDL-c near optimal/above optimal $(129 \mathrm{mg} / \mathrm{dL})$ in $83 \%$ of subjects. HDL cholesterol was lower than $40 \mathrm{mg} / \mathrm{dL}$ in $43 \%$ of patients, and triglycerides were above normal $(<150 \mathrm{mg} / \mathrm{dL})$ in $79 \%$ of patients. There were no differences in lipid values between subjects at high or very high cardiovascular risk (Table 1).

Very high cardiovascular risk was significantly more frequent in women $(57 \% ; \mathrm{p}=0.02)$. Treatment resulted in a significant reduction of total and LDL cholesterol as well as triglycerides both in high and very high-risk subjects (Table 1 ).

However, the response rate to treatment ranged from $50 \%$ to $75 \%$, with no difference between high and very high-risk subjects (Figure 1). Interestingly, all three parameters (total-c, LDL-c, and triglycerides) were seen to lower in $40 \%$ and $47 \%$ in high and very high-risk patients, respectively, with no statistical difference between the groups. Finally, improvement in the lipid profile - total-c, LDL-c and triglyceride reductions plus HDL-c increase was evidenced in only $21 \%$ and $28 \%$, respectively, with no statistical difference between the groups.

Regarding the LDL-c goal attainment (NCEP-ATP III therapy guidelines), only 24 (19\%) high-risk subjects achieved an LDL-c $<100 \mathrm{mg} / \mathrm{dL}$, while a significantly lower percentage $(p=0.04)$ of subjects at very high cardiovascular risk reached an LDL-c $<70 \mathrm{mg} / \mathrm{dL}(11 \%$; $\mathrm{n}=30$ ). Additionally, ATP III goals were attained in a larger percentage by men (20.7\%) than women (12.6\%), although this difference was not statistically significant.

The most common pharmacological treatment was statin-based therapy, i.e. simvastatin at an initial dose of $20 \mathrm{mg}$ in $35 \%(n=68)$ of patients, or atorvastatin at an initial dose of $40 \mathrm{mg}$ in $56 \%(\mathrm{n}=110)$ of the subjects. Ezetimibe alone or in combination with simvastatin was used in 11 subjects (5.6\%). Lastly, fibrates, i.e. gemfibrozil $(600 \mathrm{mg})$ or fenofibrate $(160 \mathrm{mg})$ was the treatment prescribed to only $3 \%(n=5)$ of the patients.

In very-high risk patients, statins were used in $95.8 \%$ of the cases $(n=253)$ and in those, atorvastatin corresponded to $50 \%$, simvastatin $34.8 \%$ and rosuvastatin $11 \%$ (Table 2 ).

The 30 patients who reached the ATP III LDL-c goal were prescribed high doses of statins either alone or in combination.

\section{Discussion}

A reduction of lipid values - total-c, LDL cholesterol and/or triglycerides - in patients at high and very high cardiovascular risk was $56 \%$ and $53 \%$, respectively. Therefore, we conclude that regardless of the treatment option or its duration, approximately half of the patients did not show an improvement in lipid profile.

It was not surprising that pharmacological treatment for dyslipidemia was mainly based on statins and particularly on atorvastatin. What is surprising is that low doses have been prescribed for high-risk patients, even though it is known that the success rate of such

Table 1 - Lipid values (mg/dL) in Ecuadorian subjects categorized by cardiovascular risk before and after pharmacological treatment for dyslipidemia

\begin{tabular}{|c|c|c|c|c|c|c|}
\hline & Age & \%Female & Total-c & LDL-c & Triglycerides & HDL-c \\
\hline \multirow[t]{3}{*}{ High risk $(\mathrm{n}=125)$} & $54.1 \pm 14.3$ & 48.0 & $235 \pm 60$ & $151 \pm 62$ & $271 \pm 195$ & $49 \pm 26$ \\
\hline & & & $212 \pm 55$ & $135 \pm 52$ & $204 \pm 156$ & $48 \pm 26$ \\
\hline & & & 0.018 & 0.03 & 0.003 & 0.76 \\
\hline \multirow[t]{3}{*}{ Very high risk $(n=264)$} & $62.6 \pm 11.7$ & 57.2 & $228 \pm 54$ & $140 \pm 50$ & $268 \pm 285$ & $43 \pm 13$ \\
\hline & & & $197 \pm 51$ & $123 \pm 45$ & $208 \pm 152$ & $44 \pm 13$ \\
\hline & & & $<0.0001$ & $<0.0001$ & 0.003 & 0.37 \\
\hline
\end{tabular}




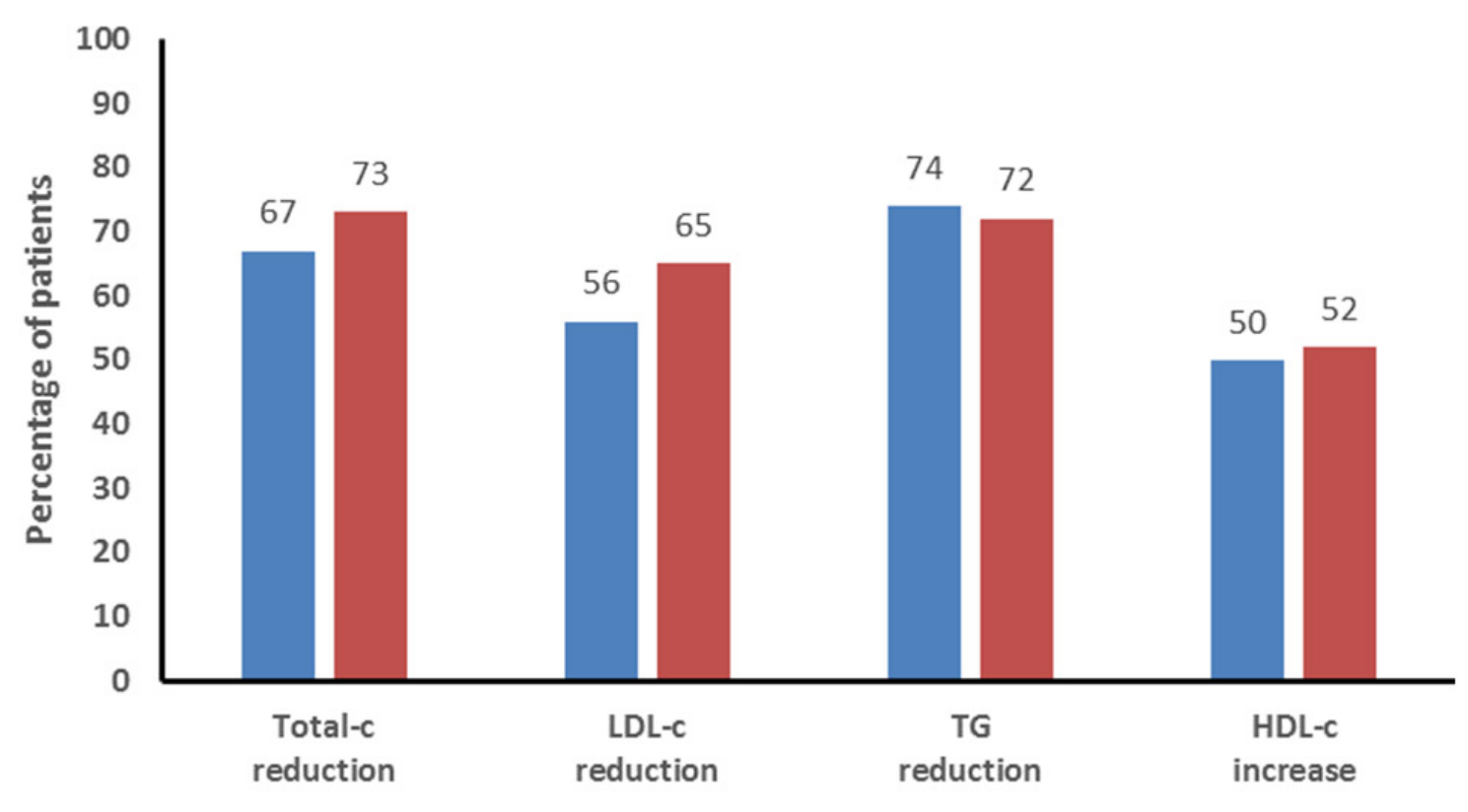

High risk $\square$ Very high risk

Figure 1 - Response rate (improvement of lipid profile) in Ecuadorian patients after treatment for dyslipidemia. Total-C: total cholesterol; LDL-c: low-density lipoprotein cholesterol; HDL-c: high-density lipoprotein cholesterol.

doses is low. ${ }^{7}$ It is also to be noted that fibrates have been prescribed to high-risk patients, given that recent trials have shown that these medications have failed to achieve a statistically significant reduction in lipid levels and, when combined with statins, have shown an increase in side effects. ${ }^{8}$

Moreover, the use of ezetimibe, particularly in association with statins, was found to be reduced. This may be explained by the fact that ezetimibe is not included in the National Essential Medicines List, which is a mandatory reference in public institutions. In private institutions, however, we could not find a clear explanation other than a misinterpretation of ATP III therapeutic goals by physicians.

In 2013, a new set of recommendations for the management of dyslipidemia were released by the American College of Cardiology (ACC) in collaboration with the American Heart Association (AHA). These guidelines refer to overall atherosclerotic cardiovascular disease and differ significantly from the previous ATP III guidelines by the fact that LDL-C and non-HDL-c goals were completely abolished. ${ }^{9}$ In addition, ATP III and subsequent updates state that the decrease in the lipid profile solely is not enough to reduce cardiovascular risk. ${ }^{10}$

Our analysis shows that the achievement of ATPIII treatment goals by patients at high risk was no different between statin therapies, i.e. $22 \%$ atorvastatin at $40 \mathrm{mg}$, $18.2 \%$ simvastatin at $40 \mathrm{mg}$ and $18.8 \%$ rosuvastatin at $20 \mathrm{mg}$. Atorvastatin in higher doses allowed an additional 15\% while no increase was found with higher doses of simvastatin or rosuvastatin. In patients at very high-risk, the ATPIII LDL-C goals were achieved by $18.4 \%$ of patients taking atorvastatin at $40 \mathrm{mg}, 7.6 \%$ of patients taking simvastatin and $3.6 \%$ of patients taking rosuvastatin. The use of higher doses did not result in a difference in success rates for LDL-c goal achievement.

We also analyzed our results based on the 2013 ACC/ AHA guidelines as reference, and found that although $94 \%$ of the patients required a high-intensity statin therapy (atorvastatin at $40 / 80 \mathrm{mg}$ or rosuvastatin at $20 / 40 \mathrm{mg}$ ), only $35.4 \%$ of patients actually received it, and from these, only $10.7 \%$ reached the expected goal of $50 \%$ reduction LDL-c. ${ }^{9}$

Our results are comparable to those reported in a study conducted in Mexico, which showed that therapeutic 
Table 2 - Distribution of pharmacological therapy for dyslipidemia in Ecuadorian patients at very high cardiovascular risk $(n=253)$

\begin{tabular}{lcccc}
\hline & $10 \mathrm{mg}$ & $20 \mathrm{mg}$ & $40 \mathrm{mg}$ & $80 \mathrm{mg}$ \\
\hline $\begin{array}{l}\text { Atorvastatin } \\
(\mathrm{n}=132)\end{array}$ & $2(0.8 \%)$ & $23(9.1 \%)$ & $78(30.8 \%)$ & $29(11.5 \%)$ \\
$\begin{array}{l}\text { Simvastatin } \\
(\mathrm{n}=92)\end{array}$ & $2(0.8 \%)$ & $47(18.6 \%)$ & $39(15.4 \%)$ & $4(1.6 \%)$ \\
$\begin{array}{l}\text { Rosuvastatin } \\
(\mathrm{n}=29)\end{array}$ & $9(3.5 \%)$ & $8(3.2 \%)$ & $12(4.7 \%)$ & -- \\
\hline & $100 \mathrm{mg}$ & $160 \mathrm{mg}$ & $300 \mathrm{mg}$ & $600 \mathrm{mg}$ \\
\hline $\begin{array}{l}\text { Gemfibrozil } \\
(\mathrm{n}=26)\end{array}$ & -- & -- & $1(1.9 \%)$ & $25(46.3 \%)$ \\
$\begin{array}{l}\text { Fenofibrate } \\
(\mathrm{n}=28)\end{array}$ & $1(1.9 \%)$ & $2(3.7 \%)$ & $2(3.7 \%)$ & $23(42.6 \%)$ \\
\hline $\begin{array}{l}\text { Ezetimibe } \\
(\mathrm{n}=6)\end{array}$ & $6(75.0 \%)$ & & \\
$\begin{array}{l}\text { Ezetimibe } \\
10 \text { mg + } \\
\text { simvastatin } \\
(\mathrm{n}=2)\end{array}$ & $2(25.0 \%)$ & & \\
\hline & $10 \mathrm{mg}$ & & \\
\hline
\end{tabular}

goals were attained by $29 \%$ of subjects taking initial dose of statin therapy and and after statin dosage adjustment $42 \%$ of the subjects reach the goal at the end of the study. ATPIII therapy goals were better attained in groups at a lower risk. ${ }^{11}$

As we described in the preliminary analysis of the results, previously published by our group,$^{12}$ physicians are probably not evaluating the total lipid profile when selecting and monitoring the therapy. Evidence of this is: a) nearly half of the subjects had a total cholesterol reduction and showed a $60 \%$ reduction in triglycerides; b) all three parameters (total-c, LDL-c and triglycerides) were reduced in almost $43 \%$ of the subjects; and c) $70 \%$ of the study population had mixed hyperlipidemia.

In this sense, although it may be appropriate to adhere to treatment guidelines that recommend addressing LDL-C levels as the first step, it is important to deeper evaluate and treat these patients. ${ }^{13}$

Adherence to treatment is an important factor that affects the success of reaching the proposed target and is highly dependent on educational and motivational interventions. ${ }^{14}$ Previous studies on adherence to statin treatment showed that in longer periods of time (6 months), around $50-60 \%$ patients continue on treatment. ${ }^{15,16}$ Treatment adherence was not considered in the present study, but we previously reported that one out of four patients ( $25 \%$ ) stated to have forgotten at least one dose of their treatment, regardless of disease and duration of treatment. ${ }^{17}$

Although the retrospective design of the study and the lack of a stratified sampling constitute limitations to the analysis of the results, we conclude that there is a very low rate of ATP III therapy goal achievement among patients with dyslipidemia categorized as high and very high cardiovascular risk, independently of the treatment option or its duration. This can be attributed to the prescription of low doses of statins and to potential confounders like the simplistic evaluation of isolated lipid fractions rather than the complete lipid profile.

\section{Author contributions}

Conception and design of the research: Hernández I, Estrella A, Salazar J, Duarte Y, Torres E, López C, Terán S, Mendoza A, Terán E. Acquisition of data: Salazar J, Duarte Y, Torres E, López C, Terán S, Mendoza A. Analysis and interpretation of the data: Hernández I, Estrella A, Salazar J, Duarte Y, Torres E, López C, Terán S, Terán E. Statistical analysis: Terán S, Mendoza A, Terán E. Obtaining financing: Estrella A. Writing of the manuscript: Hernández I, Estrella A, Terán E. Critical revision of the manuscript for intellectual content: Hernández I, Estrella A, Salazar J, Duarte Y, Torres E, López C, Terán S, Mendoza A, Terán E.

\section{Potential Conflict of Interest}

No potential conflict of interest relevant to this article was reported.

\section{Sources of Funding}

This study was funded by Pontificia Universidad Catolica del Ecuador.

\section{Study Association}

This study is not associated with any thesis or dissertation work. 


\section{Ethics approval and consent to participate}

This study was approved by the Ethics Committee of the USFQ under the protocol number 2015-044IN. All the procedures in this study were in accordance with the 1975 Helsinki Declaration, updated in 2013. Informed consent was obtained from all participants included in the study.

\section{References}

1. Stringhini S, Carmeli C, Jokela M, Avendaño M, McCrory C, d'Errico $\mathrm{A}$, et al, Socioeconomic status, non-communicable disease risk factors, and walking speed in older adults: multi-cohort population based study. BMJ. 2018;360:k1046.

2. GBD 2015 Risk Factors Collaborators. Global, regional, and national comparative risk assessment of 79 behavioural, environmental and occupational, and metabolic risks or clusters of risks, 1990-2015: a systematic analysis for the Global Burden of Disease Study 2015. Lancet. 2016;388(10053):1659-724.

3. Ecuador.Ministerio de Salud Publica del Ecuador. Anuario De Vigilancia Epidemiológica 1994 - 2016. Enfermedades Crónicas No Transmisibles. Report; 2018.

4. López-Cevallos D. Tomo I: Encuesta Nacional de Salud y Nutrición de la población ecuatoriana de cero a 59 años. ENSANUT-ECU 2012 por Freire Wilma, et al Rev Mundos Plurales. 2015;2(1):119-21.

5. National Cholesterol Education Program (NCEP) Expert Panel on Detection, Evaluation, and Treatment of High Blood Cholesterol in Adults (Adult Treatment Panel III). Third Report of the National Cholesterol Education Program (NCEP) Expert Panel on Detection, Evaluation, and Treatment of High Blood Cholesterol in Adults (Adult Treatment Panel III) final report. Circulation. 2002;106(25):3143-421.

6. Cholesterol Treatment Trialists' (CTT) Collaborators, Mihaylova B, Emberson J, Blackwell L, Keech A, Simes J, et al. The effects of lowering LDL cholesterol with statin therapy in people at low risk of vascular disease: meta-analysis of individual data from 27 randomised trials Lancet. 2012;380(9841):581-90.

7. Cholesterol Treatment Trialists' (CTT) Collaboration, Baigent C, Blackwell L, Emberson J, Holland LE, Reith C, et al. Efficacy and safety of more intensive lowering of LDL cholesterol: a meta-analysis of data from 170000 participants in 26 randomised trials. Lancet. 2010;376(9753):1670-81

8. Sando KR, Knight M. Nonstatin therapies for management of dyslipidemia: a review. Clin Ther. 2015;37(10):2153-79.

9. Stone NJ, Robinson JG, Lichtenstein AH, Merz NB, Blum CB, Eckel RH, et al. 2013 ACC/AHA Guideline on the Treatment of Blood Cholesterol to Reduce Atherosclerotic Cardiovascular Risk in Adults. Circulation. 2014;129(25 suppl 2):S1-S45.

10. National Institutes of Health. National Cholesterol Education Program. Third Report of the National Cholesterol Education Program (NCEP) Expert Panel on Detection, Evaluation, and Treatmentof High Blood Cholesterol in Adults (Adult Treatment Panel III). NIH: Maryland; 2002. (Final Report: 02-5215).

11. Meaney E, Vela A, Ramos A, Alemao E, Yin D. Cumplimiento de las metas con reductores del colesterol en pacientes mexicanos. El estudio COMETA México. Gac Med Mex. 2004;140(5):493-501.

12. Estrella A, Hernandez I, Salazar J, Duarte Y, Teran E. ATPIII goals accomplishment with the different treatments for dyslipidemia at the hospital centers in Quito and Guayaquil. Rev Fac Cien Quim. 2016;ed esp:35-40.

13. Stacy TA, Egger A. Results of retrospective chart review to determine improvement in lipid goal attainment in patients treated by highvolume prescribers of lipid-modifying drugs. J Manag Care Pharm. 2006;12(9):745-51.

14. Chung PW, Yoon BW, Lee YB, Shin BS, Kim HY, Park JH, et al. Medication adherence of statin users after acute ischemic stroke. Eur Neurol. 2018;80(1-2):106-14.

15. Lansberg P, Lee A, Lee ZV, Subramaniam K, Setia S. Nonadherence to statins: individualized intervention strategies outside the pill box. Vasc Health Risk Manag. 2018 May 24;14:91-102.

16. A Vonbank A, Drexel H, Agewall S, Lewis BS, Dopheide JF, Kjeldsen $\mathrm{K}$, et al. Reasons for disparity in statin adherence rates between clinical trials and real-world observations: a review. Eur Heart J Cardiovasc Pharmacother. 2018;4(4):230-6.

17. Hernandez I, Sarmiento N, Gonzalez I, Galarza S, Bastida A, Teran S, et al. Adherence to treatment in outpatient patients of health centers in Quito. Rev Metro Ciencia. 2018;26(1);7-11. 